\title{
Empirical Study on the Measurement of the Technical Efficiency of Jilin Province's Five High-tech Industries
}

\author{
Jie Yao , Huan Ma \\ School of Economy and Management, Northeast Dianli University, 132012 Jilin, China
}

\begin{abstract}
This paper first analyzed the industrial distribution of Jilin province's high-tech enterprises, and then selected 13 input and output indicators based on analyzing the influence factors of high-tech industry. Through the correlation analysis between each indicator's relevant data, the paper constructed the technical efficiency evaluation model of Jilin Province's high-tech industries including 12 indicators. After that it measured the technical efficiency of Jilin Province's five high-tech industries from 2004 to 2013 by using DEA analysis method. Finally, this paper drew conclusions and gave suggestions.
\end{abstract}

\section{Introduction}

Since the 21st century, China's high-tech industry has made great achievements and become the pillar industry in China's national economy. According to the classification method in "China statistics yearbook on high technology", high-tech industry can be divided into five major industries, including manufacture of medicines, manufacture of aircrafts and spacecrafts, manufacture of electronic equipment and communication equipment, manufacture of computers and office equipments, manufacture of medical equipments and measuring instrument.

At present, many scholars have carried out research work on the related issues of high-tech industry.

Some scholars have done some research work on the technical efficiency of high-tech industry, for example, Liu Junling (2016) has done empirical study on the efficiency of China's high-tech industry based on PCA and three-stage DEA model [1]. Based on factor analysis and data envelopment analysis method, Qi Yuan etc. (2014) have made empirical study on the technical efficiency of Beijing's high-tech industry from 1996 to 2010. Firstly, the index systems are established through methods of literature research and factor analysis, and then the technical efficiency is measured based on data envelopment analysis on Malmquist productivity index and $\mathrm{C}^{2} \mathrm{R}$ model respectively. The results show that the combination method of factor analysis and data envelopment analysis is feasible, and the technical efficiency of Beijing has reached efficiency since 1999 [2]. Feng Peng ect. (2012) examined the relationship between technology imports, R\&D investment and technical efficiency of Chinese high-tech industry using provincial panel data for the period between 2000 and 2009[3].
Some scholars have done some research work on the innovation efficiency and R\&D efficiency of high-tech industry. For example, Zhao Shukuan etc. (2013) have constructed the evaluation index system and model of the innovation efficiency of high-tech enterprises, and evaluated the innovation activities of 151 high-tech enterprises in Jilin Province from four aspects, including efficiency, effectiveness, returns to scale and projection analysis [4]. Based on value chain perspective, $\mathrm{Yu}$ Yongze and his partners (2010) have divided the research and development process of high-tech industry into two stages, technology development and transformation of technological achievements, by using DEA model with slack variables, and have done empirical study on its efficiency and influence factors [5]. Han Jing (2010) analyzed the innovation efficiency of China's high-tech industry by using SFA method [6]. Huang Shun and Guan Yan (2010) have divided the whole process of technological innovation into two stages, including technology output and technology transformation, and have measured the technological innovation efficiency of China's high-tech industry from 1999 to 2007 by using two-stage DEA model [7]. Guan Jiancheng and Chen Kaihua (2009) have measured the technical efficiency, pure technical efficiency, scale efficiency and scale state of the technological innovation activities of China's hightech industry by using data envelopment analysis model with slack variables and critical efficiency measurement model [8].

And some other scholars have done some research work on the competitiveness of high-tech industries in various regions. For example, Liu Yannan ect. (2011) have done empirical analysis on the competitiveness of Liaoning Province's High-tech Industry based on factor analysis method [9]. Liu Zhaode etc. (2009) have comprehensively evaluated the competitiveness of 
Guangdong Province's and other 11 provinces' High-tech industry [10].

Due to the relatively few studies on the five major high-tech industries, this paper took it as a breakthrough point, and made empirical study on the technical efficiency of Jilin Province's five high-tech industries by using data envelopment analysis method.

\section{Industrial distributions of High-tech enterprises in Jilin Province}

After years of development, high-tech enterprises in Jilin province have taken shape, many enterprises have developed rapidly, and renowned both at home and abroad.

A number of pharmaceutical companies, such as Jilin Aodong Pharmaceutical Ltd, Xiuzheng Pharmaceutical Ltd, Jilin Changbai Mountain Medicine Company, and so on, have made Jilin become a large pharmaceutical manufacture province ahead of other provinces.

The enterprises, such as First Automotive Works, Huawei Electronics Ltd, Jilin Chemical Industry Group Corporation, Shenhua New Energy Corporation, and so on, have maintained strong growth momentum so that Jilin province has reached the leading domestic level in automobile manufacturing industry, microelectronics, chemical industry and new energy development.

The total number of high-tech enterprises in China has been 26894 by the end of 2013. And 394 enterprises of them are located in Jilin Province, accounting for only $1.47 \%$ of the total. Therefore, there is still a gap from the national average level.

The industrial distribution of high-tech enterprises in Jilin Province from 2007 to 2013 has been shown in Fig. 1.

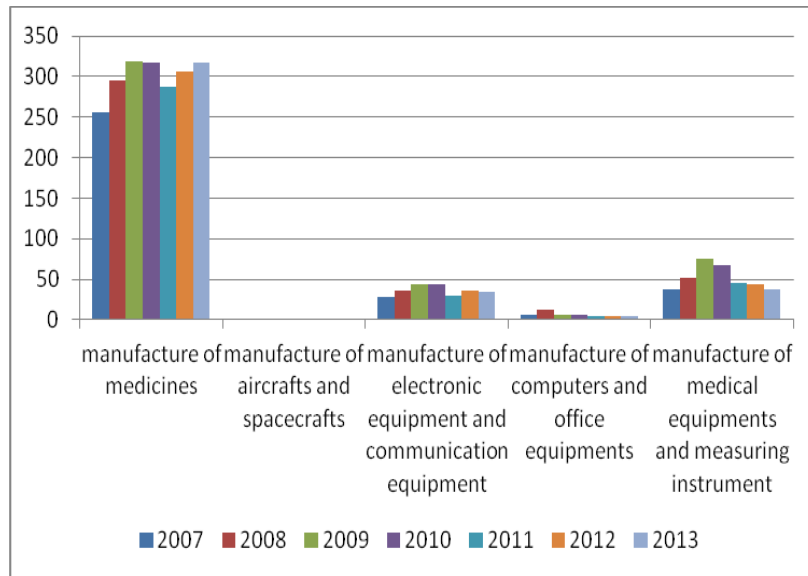

Figure 1. Industrial distribution of high-tech enterprises in Jilin Province.

It can be seen from Fig. 1 that the high-tech enterprises of Jilin Province mainly concentrate in the following industries, including manufacture of medicines, manufacture of electronic equipment and communication equipment, manufacture of medical equipments and measuring instrument. There are few enterprises in the next two industries, manufacture of aircrafts and spacecrafts, and manufacture of computers and office equipments. Therefore, the development of these two industries is slow.

\section{Construction of technical efficiency evaluation model}

\subsection{Model construction method}

In this research, data envelopment analysis (DEA) method was used. Although DEA methods are diverse, but generally there are two main types.

One is to set the output value in advance, and under this premise the purpose of the research work is to compute the input proportion which can be reduced to the utmost. This method is also known as input-oriented DEA method.

The second is just opposite to the first one. Considering input as fixed value, it wants to see how much of the output can be increased proportionally, so it is known as output-oriented DEA method.

Considering the actual situation, this article selects the output-oriented BCC model to measure and evaluate the technical efficiency of Jilin province's high-tech industry. BCC model is a very practical and effective efficiency measurement model. It can complete the measurement of the technical efficiency with multiple input and output indexes, so it is suitable for measuring high-tech industry' technical efficiency.

\subsection{Construction of evaluation model}

Considering the characteristics of high-tech industry, this paper argues that the development of high-tech industry is mainly influenced by the following four aspects, including its economic capacity, technological innovation capability, the support environment and its development scale.

During the process of selecting indexes, we mainly considered about the following two aspects. On one hand, the indexes can measure the actual capacity of high-tech industry comprehensively so that the government can predict the prospects of high-tech enterprises. On the other hand, they can be used in the dynamic study of technical efficiency and then be optimized.

According to the principle of index selection, among the factors affecting the development of high-tech industries, the input indexes selected include R\&D Fulltime Equivalent (man-year), Expenditure on New Product Development (100 million RMB yuan), Number of S\&T Institutions (unit), Expenditure for Acquisition of Foreign Technology (100 million RMB yuan), Expenditure on Technical Renovation (100 million RMB yuan), Number of Enterprises (unit), Annual Average Number of Employed Personnel (person), Newly Increased Fixed Assets (100 million RMB yuan), which are represented by $\mathrm{X}_{1}, \mathrm{X}_{2}, \mathrm{X}_{3}, \mathrm{X}_{4}, \mathrm{X}_{5}, \mathrm{X}_{6}, \mathrm{X}_{7}, \mathrm{X}_{8}$ respectively.

And the output indexes selected include Revenue from Principal Business (100 million RMB yuan), Taxes and Profits (100 million RMB yuan), Exports (100 million RMB yuan), Sales Revenue of New Products 
(100 million RMB yuan), Owning Inventive Patent (unit), which are represented by $\mathrm{Y}_{1}, \mathrm{Y}_{2}, \mathrm{Y}_{3}, \mathrm{Y}_{4}, \mathrm{Y}_{5}$ respectively.

The input and output indexes above were made correlation analysis first by using SPSS22.0 software to ensure that those indexes final selected are logically correlated but not numerically correlated. The analysis result shows that the input index $\mathrm{X}_{4}$ is not suitable, so we eliminate this factor and establish the evaluation model finally, as shown in Fig. 2.

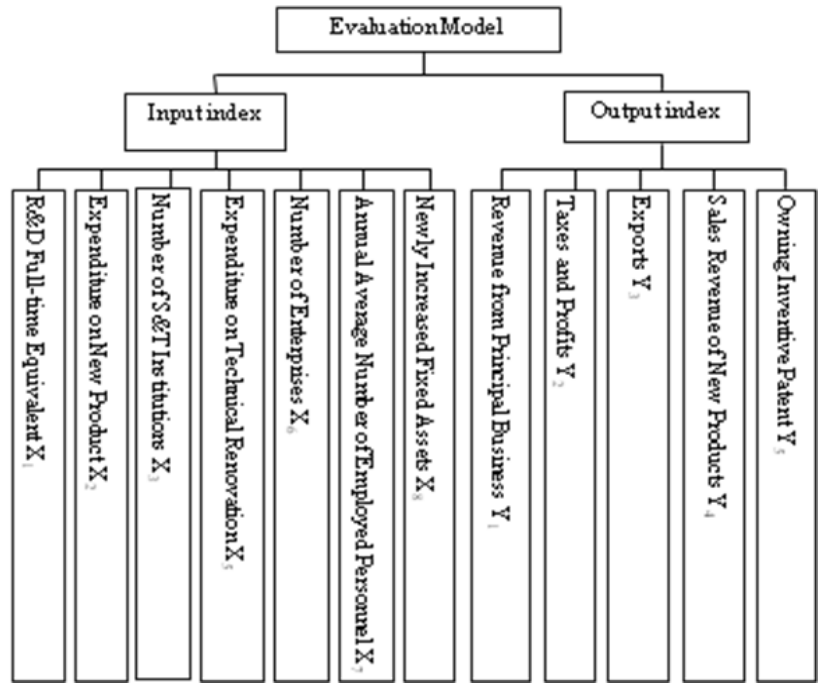

Figure 2. Evaluation model of the technical efficiency of Jilin Province's high-tech industry.

\section{Empirical analysis of the technical efficiency of Jilin Province's five major High-tech industries}

According to the evaluation model established, the paper analyzed each index's corresponding data of the five high-tech industries in Jilin Province from 2004 to 2013.

By using deap2.1 software, this paper finally got the measure results of technical efficiency, pure technical efficiency and scale efficiency of Jilin Province's five high-tech industries. (Note: The data are sourcing from "Statistical Yearbook of China's High-tech Industry from 2005 to 2014".)

\subsection{Measure result of technical efficiency}

The measure result of technical efficiency of Jilin Province's five major high-tech industries from 2004 to 2013 is shown in Fig. 3.

It can be seen from Fig. 3 that, under the condition of constant scale, the technical efficiency of manufacture of computer and office equipment has maintained to be 1 , showing that this industry has been continuously technical effective among all the five major high-tech industries of Jilin Province.

The technical efficiencies of manufacture of aircrafts and spacecrafts, and manufacture of electronic equipment and communication equipment are also very high. They have not realized effective technical efficiency only once in ten years, with the average value to be 0.99 and 0.96 respectively.

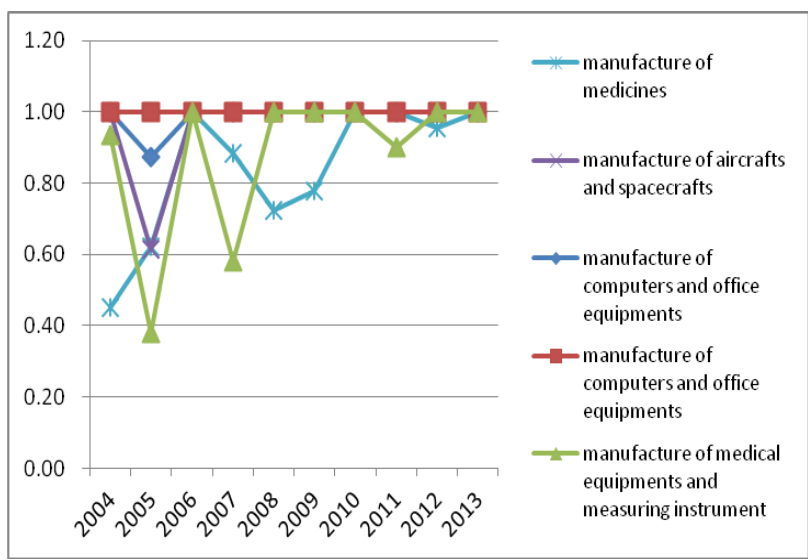

Figure 3. Measure result of the technical efficiency of Jilin Province's five major high-tech industries

Only the technical efficiency of manufacture of medicines and manufacture of medical equipments and measuring instrument are not stable. Although these two industries have realized effective technical efficiency for four years and six years respectively during the period of ten years, but they have shown a trend of fluctuations in general, indicating that these two industries still need to be further developed and enhanced.

\subsection{Measure result of pure technical efficiency}

The measure result of pure technical efficiency of Jilin Province's five major high-tech industries from 2004 to 2013 is shown in Fig. 4.

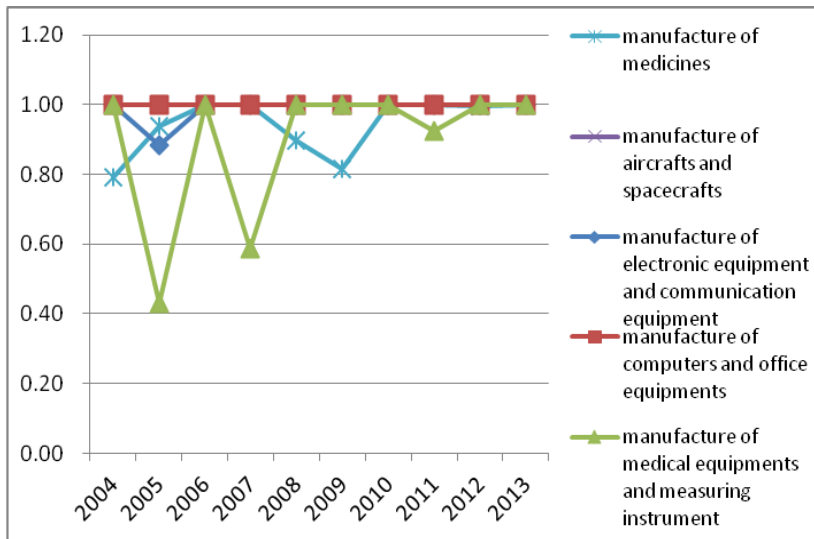

Figure 4. Measure result of the pure technical efficiency of Jilin Province's five major high-tech industries

As shown in Fig. 4, under the condition of variable scale, all the others of Jilin Province's five major hightech industries have basically maintained to be effective in technical efficiency with their average efficiency value to be close to or equal to 1 , except the following two industries, manufacture of medicines and manufacture of medical equipments and measuring instrument, with their average efficiency value to be 0.94 and 0.89 respectively.

It shows that, under the condition of variable scale, the technical efficiency of these three industries has been configured reasonably, the resources have been utilized effectively, and they have basically realized the sustainable developing mode. 


\subsection{Measure result of scale efficiency}

The measure result of scale efficiency of Jilin Province's five major high-tech industries from 2004 to 2013 is shown in Figure 5.

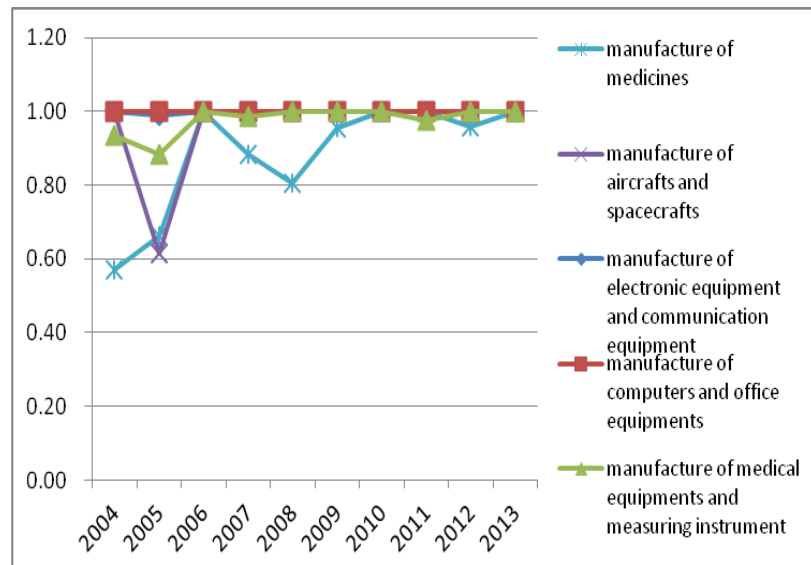

Figure 5. Measure result of the scale efficiency of Jilin Province's five major high-tech industries

It can be seen from Fig. 5 that, during the ten years, the scale efficiency value of the following two industries, manufacture of electronic equipment and communication equipment, and manufacture of computer and office equipment, has maintained to be 1 , showing that these two industries have been continuously effective in scale.

The scale efficiency value of the next two industries, manufacture of medical equipments and measuring instrument and manufacture of aircrafts and spacecrafts, is also very high, with the average value to be 0.98 and 0.96 respectively.

Only the average value of manufacture of medicines is relatively low, it is only 0.88 . And the overall volatility is relatively clear, indicating that the development of this industry is not stable enough.

\section{Conclusion}

Based on the empirical research above, this paper draws the following conclusions.

First, despite the good developing momentum of Jilin Province's high-tech industry, there still exists a phenomenon of wasting resources. Therefore, the government needs to formulate corresponding policies that are helpful for the development of high-tech industry, and each enterprise also needs to adjust its management system and resource inputs, striving to maintain a fast, scientific and sustainable developing trend.

Second, both technical efficiency and scale efficiency have been realized in the industries of manufacture of electronic equipment and communication equipment, and manufacture of computer and office equipment. So these two industries should continue to maintain their current developing level and further consolidate their pillar status in the development of Jilin Province's high-tech industries.

Third, manufacture of medicines and manufacture of medical equipments and measuring instrument are the weak links of Jilin Province's high-tech industries. With larger scale but insufficient output, these two industries should be paid close attention to and put under effective control and management by the government.

Finally, although manufacture of aircrafts and spacecrafts has maintained to be technically efficient since 2006, but its overall scale is still small. Therefore, the government should increase investment in this industry in order to support its development.

\section{Acknowledgment}

This research was financially supported by the Social Science Foundation of Jilin Province "Empirical study on the influence factors and efficiency measurement of wind energy development and utilization in Jilin Province" (Grant NO.2016JD58) and the 12th Five-Year planning project of Jilin Province's Education Department "Empirical Study on the Measurement and Evaluation of the Technical Efficiency of Jilin Province's High-tech Industry" (Grant NO.2015-171).

\section{References}

1. L. Junling, Liaoning Tech. Univ. J. (Soc. Sci. E.) 01, 25-32 (2016)

2. Q. Yuan, Z. Yongan, Sci. and Tech. Mgmt. Res. J. 04, 43-48 (2014)

3. F. Peng, L. Li, Proc. of 2012 IEEE 19th Int. Con. on Ind. Eng. and Eng. Mgmt. (IE\&EM 2012) 10, 2623 2625 (2012)

4. Z. Shu Kuan, Y. Haiqing, G. Shunlong, Sci. Res. Mgmt. J. 02, 36-43 (2013)

5. Y. Yongze, W. Peng, L. Jianbing, Sci. Learn and Mgmt. of Sci. and Tech. J. 05, 60-65 (2010)

6. H. Jing, Sci. Res. J. 03, 467-472 (2010)

7. H. Shun, G. Yan, Indus. Tech. Econ. J. 01, 92-97 (2010)

8. G. Jiancheng, C. Kaihua, QTY Econ. and Tech. Res. J. 10, 19-33 (2009)

9. C. Hongchuan, Soft Sci. J. 08, 21-23 (2010)

10. L. Zhaode, Z. Weiguo, H. Mingliang, Tech. and Econ. J. 01, 46-49 (2009) 